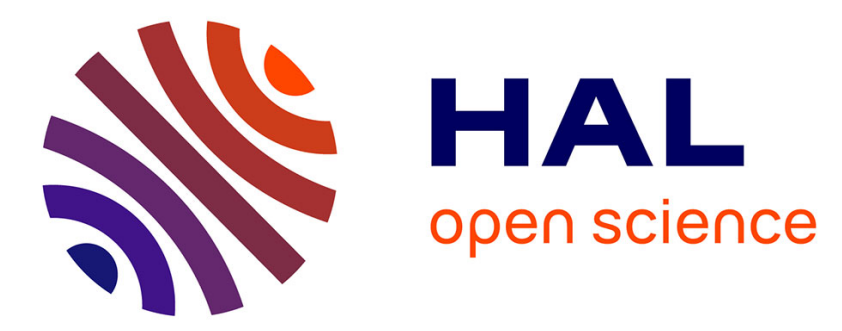

\title{
Self-Reference Effect and the Group-Reference Effect in the Recall of Shared and Unshared Information in Nominal Groups and Interacting Groups
}

Dennis D. Stewart, Cheryl B. Stewart, Jason Walden

\section{- To cite this version:}

Dennis D. Stewart, Cheryl B. Stewart, Jason Walden. Self-Reference Effect and the Group-Reference Effect in the Recall of Shared and Unshared Information in Nominal Groups and Interacting Groups. Group Processes and Intergroup Relations, 2007, 10 (3), pp.323-339. 10.1177/1368430207078693 . hal-00571653

\section{HAL Id: hal-00571653 \\ https://hal.science/hal-00571653}

Submitted on 1 Mar 2011

HAL is a multi-disciplinary open access archive for the deposit and dissemination of scientific research documents, whether they are published or not. The documents may come from teaching and research institutions in France or abroad, or from public or private research centers.
L'archive ouverte pluridisciplinaire HAL, est destinée au dépôt et à la diffusion de documents scientifiques de niveau recherche, publiés ou non, émanant des établissements d'enseignement et de recherche français ou étrangers, des laboratoires publics ou privés. 


\title{
Self-Reference Effect and the Group-Reference Effect in the Recall of Shared and Unshared Information in Nominal Groups and Interacting Groups
}

\author{
Dennis D. Stewart \\ University of Minnesota. Morris \\ Cheryl B. Stewart \\ University of Minnesota. Morris \\ Jason Walden \\ University of Minnesota. Morris
}

\begin{abstract}
We investigated how variables that have been studied at the individual level may apply at the group level. Specifically, we examined how the self-reference effect (SRE) and the groupreference effect (GRE) impacted total information recall by examining the difference between interacting groups and nominal groups. Additionally, we also examined how the SRE and GRE might impact upon the recall of shared and unshared information by comparing nominal and interacting groups. Results were supportive for the SRE affecting the total recall of information as well as the recall of shared and unshared information. However, the impact of the GRE on group recall was mixed. Theoretical and applied implications are considered.
\end{abstract}

KEYWORDS group memory, group-reference effect, self-reference effect

Previous research on memory has been done largely at the individual level. However, recently researchers have become interested in understanding how groups recall information (Clark \& Stephenson, 1989; Hartwick, Sheppard, \& Davis, 1982; Weldon, 2001). One major finding from this research has been that groups recall more information than individuals over a variety of tasks (e.g. Stephenson, Clark, \& Wade, 1986; Vollrath, Sheppard, Hinsz \& Davis, 1989).
However, when group size is equated for by using nominal groups (i.e. groups which do not interact, but instead have their non-redundant

\section{Author's note}

Address correspondence to Dennis D.

Stewart, University of Minnesota, Morris, Psychology Department, 109 Camden Hall, 600 East 4th Street, Morris, MN 56267-2134, USA [email: stewartd@morris.umn.edu] 
items summed) then nominal groups recall more information than interacting groups (e.g. Weldon \& Bellinger, 1997; Weldon, Blair, \& Huebsch, 2000), which is a finding we expect to replicate (Hypothesis 1). Together these findings have led researchers to investigate a number of variables that might affect groups' recall, such as: confidence (Hinsz, 1990; Stephenson et al., 1986), information type (Stewart \& Stewart, 2001; Tindale \& Sheffey, 2002), retrieval strategies (Basden, Basden, Bryner, \& Thomas, 1997), and motivational incentives (Weldon et al., 2000).

The current research seeks to understand how aspects of the personal self (i.e. individual traits and qualities) and social self (i.e. identification with relevant social groups) impact upon group recall. Little research has been done in this area and we find its omission interesting for two reasons. First, we believe it is commonplace for the self to affect group recall. For example, team members recalling information about past successes might recall information that highlights both their personal achievements and their collective achievements. Second, the self has been relatively ignored in collective recall despite its importance in other areas of group research (e.g. optimal distinctiveness theory, Brewer, 2003; social identity theory, Hogg, 2003).

In the following, we explore studies that at least indirectly indicate how the personal self and social self may affect group recall. First, transactive memory (TM) systems (Wegner, 1986) occur when group members use knowledge of each other's areas of expertise to coordinate group recall. That is, group members may rely on each other to store and recall information because it falls within their domain of expertise. Research on TM systems is connected to the personal self because expertise is a form of self-knowledge (i.e. I am the expert on taxes). Research has shown that TM systems facilitate group recall and that either the absence or interference of a TM system inhibits group recall (Wegner, Erber \& Raymond, 1991). Second, a study by Clark, Stephenson, and Kniveton (1990) suggests that the social self might affect group recall. They had police officers or students watch a simulated police interrogation and then recall the information either individually or in groups. At the individual level, students and police officers did not differ in their recall. However, at the group level, police officers recalled more than students. They explain these results by suggesting that police officers have greater familiarity with the task than students. However, we wonder if police officers' stronger sense of identification with their occupation also may have contributed to their superior recall of the information. In the current study we seek to examine the impact of the self more directly by exploring how variables found to impact the personal self (i.e. self-reference effect) and social self (i.e. group reference effect) at the individual level might also impact upon the group level.

\section{The self-reference effect and group-reference effect}

The self-reference effect (SRE) is defined as 'information actively related to the self [is] better remembered than information that is processed in other ways' (Symons \& Johnson, 1997, p. 371). Rogers, Kuiper, and Kirker (1977) were the first to test for the SRE. They created a self-reference (SR) condition by having participants respond with a 'yes' or 'no' as to whether an adjective described themselves and then compared it to three other information processing conditions: structural (i.e. is the adjective in big letters); phonemic (i.e. does the adjective rhyme with another word); and semantic (i.e. does this word mean the same as another word). The prediction that participants would recall more SR words than words from the other conditions was supported.

Johnson et al. (2002) wondered if the SRE could be extended to encompass a groupreference effect (GRE; i.e. the tendency to remember items related to a salient social group better than items processed in some other manner). They compared an SRE condition, a semantic condition, and a GRE condition. (e.g. are students at $\mathrm{X}$ university aggressive) and found that both the SRE and GRE conditions were 
superior to the semantic condition. Moreover, the SRE condition and GRE condition did not differ from each other.

Symons and Johnson (1997) concluded that two theoretical explanations both contribute to the SRE: elaborative processing (e.g. Rogers et al., 1977) and organizational processing (e.g. Klein \& Kihlstrom, 1986). The elaborative processing view is derived from Craik and Tulving's (1975) depth of processing (DOP) model of memory. In the DOP model, self-reference items will receive greater elaboration (i.e. comparison between items on the list and information already known about themselves) at encoding which leads them to be more easily retrieved later. For example, if participants are asked if they are 'intelligent' then they might elaborate on this word by thinking about situations that tested their intelligence (e.g. grades). The organizational approach assumes relational processing of items on a list. Relational processing 'can include word-to-word associations and associations that emerge when words share a common category label' (Klein \& Loftus, 1988, p. 6). The connection to the SRE is that participants sort and organize memories both by associating words with each other and by dividing information into either a 'describes me' or a 'does not describe me' category. For example, the words 'angry' and 'mad' might both be associated with each other and also with the category 'describes me'. Johnson et al. (2002) also thought that organizational and elaborative processing may underlie the GRE.

Although the present study focuses on group recall, we expect to replicate Johnson et al.'s (2002) findings. Namely, individuals will have similar recall for SRE and GRE items and greater recall for both SRE and GRE items than semantic items (Hypothesis 2).

\section{SRE and GRE at the group level}

Researchers have noted that in order to have a comprehensive theory of group memory one needs to understand the interplay between individual remembering and group remembering (Clark \& Stephenson, 1989; Weldon \& Bellinger, 1997). One approach to examining this interplay is to observe whether individual level effects transfer to the group level (Weldon \& Bellinger, 1997). The few studies that have examined such a transfer suggest it occurs in a continuous manner (Badsen et al. 1997; Stewart \& Stewart, 2001; Stewart, Stewart, Tyson, Vinci \& Fioti, 2004; Weldon \& Bellinger, 1997). For example, Weldon and Bellinger (1997) found that the depth of processing effect (i.e. items given deeper processing are better recalled) and the picture-superiority effect (i.e. pictures are better recalled than words) occurred with both nominal groups and interacting groups. Moreover, they found that group interaction seemed neither to attenuate nor accentuate these effects. Given that a depth of processing explanation (i.e. elaborative processing; Rogers et al., 1977; Symons \& Johnson, 1997) has been used to explain the SRE and GRE effects, we hypothesize that the SRE and GRE will occur in both nominal groups and in interacting groups (Hypothesis 3).

\section{Attenuation versus accentuation of GRE and SRE}

Although Weldon and Bellinger's (1997) findings suggest that interacting groups neither accentuate nor attenuate individual level effects, Hinsz, Tindale, and Vollrath's (1997) review of the group information processing literature suggests that such patterns do occur. We do not think there is enough evidence to confidently predict that one pattern over the other will occur; thus we offer contrasting explanations about why group interaction might either attenuate or accentuate the SRE and GRE.

\section{Attenuation of the GRE and SRE}

Process loss occurs when the actual productivity of the group does not meet its potential productivity (Steiner, 1972). Social loafing has been proposed as one reason for process loss (Karau \& Williams, 1993). However, Weldon et al. (2000) investigated social loafing in collective recall and concluded that social loafing could not explain why interacting groups recalled less information than nominal groups. 
The implications of Weldon et al.'s findings for the present study are unclear however, since their stimuli consisted of a set of unrelated words that had no evaluative implications for the participants. In the current study, we used personality traits which may be more susceptible to social loafing because of the evaluative implications it has for the personal and social self.

Although there are several explanations for social loafing, we focus on evaluation apprehension and production blocking (Diehl \& Strobe, 1987). Evaluation apprehension occurs when group members fail to mention information because they fear negative sanctions from others. Previous research has shown that for both the personal self (e.g. Skowronski, Betz, Thompson, \& Shannon, 1991) and social self (e.g. Biernat, Vescio, \& Green, 1996) that individuals want to promote a positive identity. The desire to maintain a positive identity might exacerbate the concerns about evaluation apprehension in interacting groups. This increased concern about evaluation apprehension might cause interacting groups to bias group recall toward positive SRE and GRE items and omit negative SRE and GRE items, which would have the net effect of reducing the total amount of SRE and GRE items recalled. However, evaluation apprehension should have little effect on semantic items because they have no evaluative component. In nominal groups, evaluation apprehension should have less effect than in interacting groups because they never meet with any group members.

Production blocking is when the group members are stopped from producing ideas due to working in groups. A common example is when participants forget the recalled item before they have a chance to speak. Although the task of group members is to recall information, it is possible that in interacting groups, group members may stop to discuss items. In particular, they may be more prone to discuss SRE items and GRE items because of their evaluative implications, thus slowing down the recall of those items: this cannot happen in nominal groups since no discussion can take place.

\section{Accentuation of GRE and SRE}

Hinsz et al. (1997) found that groups tend to accentuate individual level information processing bias if it is present. For example, Vollrath et al (1989) studied mock juries and found that groups tended to exaggerate the bias of individuals to recall more pro-prosecution facts than pro-defense facts in a criminal case. Therefore, because the SRE and GRE do occur at the individual level, it would follow this line of reasoning that groups would accentuate this pattern of recall.

The tendency of groups to be more confident of their responses than individuals (Hinsz, 1990; Stephenson et al., 1986) may be one factor that helps explain this accentuation pattern. Additionally, in some instances, greater group confidence has been associated with superior memory performance of groups over individuals (Hinsz, 1990). It may be that because both the SRE and GRE items receive extra attention during encoding (i.e. elaborative or organization) that this not only improves recall of these items, but also people's confidence in these items. Moreover, given the findings that groups tend to be more confident than individuals, this added confidence for SRE items and GRE items may be greater for interacting groups than nominal groups, thus facilitating the SRE and GRE in interacting groups.

\section{Collective information sampling}

So far our discussion of the SRE and GRE has focused on the total amount of information recalled and has made no distinction between information shared by all group members and information known by only one group member (e.g. Stasser \& Titus, 2003). This distinction is important because it illustrates a fundamental way in which individual memory and group memory differ. In a group recall, group members have the ability to pool their unshared information whereas individuals are limited to recalling only their personal information. Therefore, in this section, we turn our attention toward exploring whether the SRE and the GRE will occur for both shared and unshared information. 
Previous research with decision making groups (Stasser \& Titus, 2003; Wittenbaum, Hollingshead \& Botero, 2004) and collective recall groups (Stewart \& Stasser, 1995; Stewart \& Stewart, 2001; Stewart et al., 2004) have repeatedly found that groups do not pool their resources optimally, but instead tend to mention shared information more than unshared information, which is a finding we expect to replicate (Hypothesis 4). Stasser and Titus (1987) offered the collective information sampling (CIS) model as a probabilistic explanation for why groups are biased toward shared information. The CIS model posits that groups sample items from the repository of knowledge that the group members collectively hold. Therefore, because more people are aware of shared information than unshared information, the group is more likely to select out shared information than unshared information.

Given this probabilistic explanation then one can increase the recall of unshared information by increasing its salience, thus making it more likely that individual group members would remember and recall unshared information. Several studies have found that if unshared information can be made more memorable then it is more likely to be recalled (Stewart, 1998; Stewart \& Stewart, 2001; Stewart et al., 2004). For example, Stewart and Stewart (2001) found that when unshared information was made more salient by representing it in pictorial form, it was more likely to be recalled.

Because SRE items and GRE items are processed more thoroughly (i.e. organizational and elaborative processing) than semantic items, it should have the impact of increasing their salience compared to semantic items. This leads us to hypothesize that the SRE and GRE should occur for unshared information (Hypothesis 5). Additionally, we expect shared information to benefit from being self-referent or group-referent; therefore, the SRE and GRE should also occur for shared information (Hypothesis 6). However, we think that the gains made in the SRE condition and GRE condition should be greater for unshared information than shared information. Our reasoning is that shared information is already advantaged because of the greater number of people who can potentially recall it and therefore, the gain from making it self-referent or group referent should be less than for unshared information where only one person can recall it. In other words, we expect the SRE condition and GRE condition to benefit both the recall of shared and unshared information, but the gain should be greater for unshared information than for shared information (Hypothesis 7).

The preceding discussion on collective information sampling has been based on previous research using interacting groups; and thus, we expect Hypotheses 4-7 to hold for interacting groups in our study. Although collective information sampling research has not generally looked at nominal groups (see Tindale \& Sheffey, 2002 for an exception), we believe that Hypotheses 4 through 7 will also hold for nominal groups. Even though nominal groups do not interact and therefore cannot discover which information is shared and unshared, the bias toward shared information should still be apparent. This is because when items are summed to create the nominal group score it is still true that shared information enjoys a sampling advantage since all group members can potentially contribute shared items, but only one person can contribute unshared items. Additionally, consistent with our earlier discussion, we will examine whether the SRE and GRE are attenuated or accentuated for shared information and unshared information when nominal and interacting groups are compared.

\section{Consensus of group members}

Although not the primary purpose of our study, we are also interested in exploring whether consensus among group members affects the recall of information. Hinsz (1990) noted that consensus among group members about the correctness of a response is an important determinant of whether an item is remembered by the group. In the current study, we will take a different approach to consensus and examine consensus not from the perspective of consensus about correctness, but rather consensus about 
whether participants endorse an item as being either self-referent or group-referent. Because we are approaching the idea of consensus from a different perspective than previous research, we offer no specific hypothesis on consensus, but will simply explore the research question about whether consensus on endorsement of an item as self-referent or group-referent impacts upon the SRE and GRE (Research Question 1).

\section{Method}

\section{Design}

A $2 \times 2 \times 3$ mixed factorial was obtained by varying group type (interacting group vs. nominal group), information distribution (shared vs. unshared), and encoding task (SRE vs. GRE vs. semantic). Information distribution and encoding task were repeated measures variables.

\section{Participants}

Participants completed the study as an extra credit project for a variety of lower- and upperlevel psychology classes. Participants were from the University of Minnesota at Morris, which is a small-sized public liberal arts school. Participants were assigned either to complete the recall in three-person groups or individually. Those who completed the task individually were later assigned to nominal groups. In total, we finished the study with 20 interacting groups and 19 nominal groups. Eleven individuals were dropped from all analyses. ${ }^{1}$

\section{Material}

This study used 108 personality traits from Anderson's (1968) personality-trait ratings. We used only items from the top $74 \%$ of the personality traits to avoid extremely negative traits. The items were broken down into six sets of 18 items: SRE-shared, GRE-shared, semantic-shared, SRE-unshared, GRE-unshared, and semantic-unshared. All of the sets were balanced in terms of likableness ratings from Anderson (1968). In order to control for primacy and recency effects, we included three buffer items at the beginning and the end of the stimulus materials. These buffer items were not analyzed.

The items were distributed so each group member received the same 18 SRE-shared items, 18 GRE-shared items, and 18 semanticshared items for a total of 54 shared items per member. For the unshared items, each group member received six SRE-unshared items, six GRE-unshared items, and six semantic-unshared items for a total of 18 unshared items per group member. Therefore, at the individual level, each group member had a total of 72 items ( 54 shared items plus his/her 18 unshared items). However, at the group level, there was a total of 108 items ( 54 shared items +18 unshared items from group member $1+18$ unshared items from group member $2+18$ unshared items from group member 3 ).

There were a couple of other features to note about the organization of the stimulus materials. First, the 72 stimulus items were divided over eight pages with nine items on each page (i.e. $3 \mathrm{SRE}$ items, 3 GRE items, and 3 semantic items). The trait would appear on the left of each page, with the corresponding question on the right side of each page. Second, shared information and unshared information were counterbalanced by creating another set of information in which shared information became unshared information and vice versa.

\section{Procedures}

A maximum of nine participants met in a large room to receive preliminary instructions and to sign consent forms. Initial instructions explained that we were interested in understanding how people make judgments about different characteristics of words. It was then explained how the experimenter would pace the participants through the materials by having each participant use a poster board with a window in the middle large enough to permit the viewing of one target item at a time. The experimenter paced the participants through the materials by instructing them to move their window onto the next target item approximately every 10 seconds. All participants were treated the same until they were divided into sets of participants that would complete the recall individually or in groups. 
For one third of these items, participants circled either 'yes' or 'no' indicating whether each target personality trait meant the same thing as another word (semantic items). For another third of the items, participants circled either 'yes' or 'no' as to whether each word described them (SRE items). For the final third of the items, participants circled either 'yes' or 'no' as to whether each word generally described UMM students (GRE items). After completing the task, participants engaged in a 2-minute distracter task in which they were instructed to circle as many ' $4 \mathrm{~s}$ ' as they could on a page of numbers.

Participants then were given a surprise recall task either in three-person groups or individually. For individuals, it was explained that they had 10 minutes to recall as much information as possible from the stimulus materials in any order. Additionally, they were asked to number their items as they recalled them. Participants were also provided with a summary sheet of these instructions during their recall period.

Groups received the same instructions as the individuals plus some further instructions for the group recall. They were informed that not all group members received the same information. Additionally, they were told to use a group strategy to recall items and not a strategy that simply summed individual responses. Finally, they were told that not all group members needed to agree that an item was listed for them to write it down on the recall sheet. Instead, they were told that each group must decide for themselves which items to record. Groups were provided with a summary sheet of these instructions.

After the group recall, group members individually filled out a post-recall questionnaire. The first question asked participates how much they anticipated having to recall the items on a 1 (not at all) to 7 (completely) scale. The next three questions asked participants how difficult it was to recall SRE items, GRE items, and semantic items on a 1 (easy) to 7 (difficult) scale. Participants also rated their accuracy of recall on a 1 (very inaccurate) to 7 (very accurate) scale. Finally, only participants in the interacting groups were asked about how difficult it was to recall either 'information common to all group members' lists' or 'unique to each group member's list' on a 1 (easy) to 7 (difficult) scale.

\section{Results}

\section{Dependent variable and reliability analysis}

The second and third authors on this study coded all the recall protocols. The third author was blind to the hypotheses of the study when coding the recall protocols. Furthermore, both coders were unaware of whether items were shared or unshared and whether items were SRE items, GRE items, or semantic items. Coders tallied the number of items that were recalled in a given category. They were instructed to count a word as correct if it was the correct form of the word, but not if it was a different word that meant the same thing. For example, if the correct word was 'intelligent' then 'intelligence' would count as correct, but not the word 'smart'. Items recalled more than once were counted only once in a category.

The coders coded the protocols for all the interacting groups and all the individuals. Individual scores were combined to form threeperson nominal groups. Nominal groups were formed largely by combining the individuals in a sequential manner, so the first three individuals who participated in the experiment would be nominal group 1, the second three people would be nominal group 2 and so forth. ${ }^{2}$ A nominal group was given credit for recalling an item if any one member of the group recalled the item. ${ }^{3}$

The percentage agreement was determined by taking the number of items the coders agreed upon over the total number of coded items used in the analysis. The percentage agreement between coders for recalled items was $99.1 \%$ for individuals and $98.6 \%$ for groups. Disagreements between the two coders were resolved in the following manner. If the coders disagreed about the form of the word (e.g. should 'domineering' count as 'dominant') then a third party, not involved in the experiment, made the decision about whether to include the item. If the disagreement was not about the form of the word then the first author resolved the disagreement. ${ }^{4}$ 


\section{Individual recall analyses: Hypothesis 2}

The data were analyzed in a 3 (encoding task: SRE vs. GRE vs. semantic) $\times 6$ (form) mixed factorial design. Encoding task is a repeated measure variable. In order to distribute unshared information to the groups, we created six forms. Three of these forms were used to distribute the original shared and unshared information and the other three came when we counterbalanced the information by reversing shared information and unshared information (i.e. shared became unshared and vice versa).

There was a main effect for the encoding $\operatorname{task}\left(F(2,102)=20.41, p<.05, \eta_{p(\text { partial })}{ }^{2}=.29\right)$. Individuals recalled more SRE items $(M=5.58$, $S D=2.91)$ and GRE $(M=4.53, S D=2.38)$ items than semantic items $(M=2.93, S D=1.93)$, which is consistent with Hypothesis 2 (simple comparisons used Bonferroni tests, $p<.05$ unless otherwise noted). The difference between the recall of SRE items and GRE items was marginally significant (Bonferroni test, $p<.10$ ). Neither the main effect of form $\left(F(5,51)<1, \eta_{p}{ }^{2}=.02\right)$, nor the interaction of form and encoding task $\left(F(10,102)<1, \eta_{p}{ }^{2}=.08\right)$, were significant, which shows that the SRE and GRE were equally likely to show up on all forms.

\section{Group recall}

The group recall data were analyzed in 2 (group type: nominal vs. interacting) $\times 2$ (information distribution: shared vs. unshared) $\times 3$ (encoding task: SRE vs. GRE vs. semantic) mixed factors analysis of variance (ANOVA). Information distribution and encoding task were repeated measures variables.

\section{Nominal group vs. interacting group: Hypo-} thesis 1 In support of Hypothesis 1, we found that nominal groups $(M=5.44, S D=1.05)$ recalled more information than interacting groups $(M=4.38, S D=.78),(F(1,37)=12.81$, $\left.p<.01, \eta_{p}^{2}=.26\right)$.

Total information recalled: Hypothesis 3 In Hypothesis 3, we predicted that at a minimum the SRE and GRE would occur in both nominal groups and interacting groups. A main effect for the encoding task $(F(2,74)=34.04, p<.01$, $\left.\eta_{p}^{2}=.48\right)$ indicated that all three means were significantly different from each other: SRE items $(M=6.19, S D=1.85)$, GRE items $(M=4.82$, $S D=1.56)$, and semantic items $(M=3.68, S D=1.17)$. However, the group type and encoding task interacted $\left(F(2,74)=3.26, p<.05, \eta_{p}{ }^{2}=.08\right)$. We did a simple main effect analysis of encoding task at the different levels of group type and found they were significant for both the interacting groups $(F(2,38)=16.33, p<.01$, $\left.\eta_{p}^{2}=.46\right)$, and the nominal groups $(F(2,36)=$ $\left.19.31, p<.01, \eta_{p}^{2}=.52\right)$. For interacting groups, this was due to interacting groups recalling more SRE items than either GRE items or semantic items (see Table 1). There was no significant difference between the recall of GRE items and semantic items. For the nominal groups, we found that nominal groups recalled more SRE items and more GRE items than semantic items. The difference between the SRE items and GRE items was marginally significant (Bonferroni test, $p<.10)$.

The group type and encoding task interaction suggests that the SRE held at about the same level for interacting groups and nominal groups thus supporting Hypothesis 3. However, the GRE was reduced in interacting groups compared to nominal groups thus supporting an attenuation hypothesis. There was no support for group interaction accentuating either the SRE or GRE. These findings were further supported by our analyses of effect sizes in which

Table 1. Mean recall of total amount of information recalled at the different levels of group type and encoding task

\begin{tabular}{lccc}
\hline & \multicolumn{3}{c}{ Encoding task } \\
\cline { 2 - 4 } & Semantic & GRE & SRE \\
\hline Group type & & & \\
Interacting group & $3.6_{\mathrm{a}}$ & $4.03_{\mathrm{a}}$ & $5.53_{\mathrm{b}}$ \\
& $(1.03)$ & $(1.32)$ & $(1.23)$ \\
Nominal group & $3.76_{\mathrm{a}}$ & $5.66_{\mathrm{b}}$ & $6.89_{\mathrm{b}}$ \\
& $(1.32)$ & $(1.36)$ & $(2.14)$ \\
\hline
\end{tabular}

Notes: Means in the same row with different subscripts differ at $p<.05$ using the Bonferroni test. In the nominal condition, the SRE condition and GRE condition differed at $p<.10$ using the Bonferroni test. Standard deviations are in parentheses. 
we compared separately the SRE to the semantic condition and the GRE to the semantic condition. The SRE appears to be about equally strong for both the nominal group condition $\left(\eta_{p}^{2}=.64\right)$ and the interacting group condition $\left(\eta_{p}^{2}=.62\right)$. However, the GRE is stronger in the nominal group condition $\left(\eta_{p}^{2}=.50\right)$ than the interacting group condition $\left(\eta_{p}^{2}=.07\right)$.

\section{Shared and unshared information: Hypotheses}

4-7 In support of Hypothesis 4, we found a main effect for information distribution that shows more shared information $(M=6.91, S D=1.34)$ than unshared information was recalled $(M=2.88$, $S D=1.33),\left(F(1,37)=240.97, p<.01, \eta_{p}^{2}=.87\right)$. Additionally, information distribution and encoding task interacted $(F(2,74)=10.07, p<.01$, $\left.\eta_{p}{ }^{2}=.21\right)$. We did a simple main effect analysis of encoding task at the levels of information distribution and found that they were significant for both unshared information $(F(2,76)=6.78$, $\left.p<.01, \eta_{p}{ }^{2}=.15\right)$, and shared information $(F(2$, $\left.76)=29.81, p<.01 \eta_{p}{ }^{2}=.44\right)$. At the unshared level, we found that groups recalled more SRE items than semantic items (see Table 2). However, group recall of GRE items at the unshared level did not differ from either SRE items or semantic items. Therefore, Hypothesis 5 was supported in respect to the SRE, but not the GRE. At the shared level, all differences between the SRE items, the GRE items, and the semantic items were significant. Therefore, Hypothesis 6 is supported. In Hypothesis 7, we predicted that SRE and GRE effects would be stronger for unshared information than for shared information. This prediction is not supported and appears to be reversed in the data. Finally, there was no threeway interaction $\left(F(2,74)<1, \eta_{p}{ }^{2}=.01\right)$, which suggests that our findings for Hypotheses 4-7 hold for both interacting and nominal groups.

\section{Consensus information: Research question 1}

Consensus in this case means how many group members during the encoding task circled 'yes' an item does describe them or does describe their group. Although for shared information there were four categories, we chose to combine the data so that there was either a majority 'yes'
Table 2. Mean recall of information recalled at the different levels of encoding task and information distribution

\begin{tabular}{lccc}
\hline & \multicolumn{3}{c}{ Encoding task } \\
\cline { 2 - 4 } & Semantic & GRE & SRE \\
\hline Information distribution & & & \\
Unshared & 2.28 & 2.82 & 3.54 \\
& $(1.28)$ & $(1.78)$ & $(2.26)$ \\
Shared & 5.08 & 6.82 & 8.85 \\
& $(1.95)$ & $(2.27)$ & $(2.39)$ \\
\hline
\end{tabular}

Notes: For unshared information, the semantic condition and SRE condition were the only conditions that differed from each other at $p<.05$ using the Bonferroni test. For shared information, all means in the same row differed from each other at $p<.05$ using the Bonferroni test. Standard deviations are in parentheses.

response (i.e. 3 yes, 2 yes) or a minority 'yes' response (i.e. 1 yes or 0 yes). We do not examine unshared information because groups cannot achieve consensus on these items since only one person responded to it on the encoding task.

The shared items were analyzed in a 2 (group type: nominal vs. interacting) $\times 3$ (encoding task: semantic vs. GRE vs. SRE) $\times 2$ (response: majority yes vs. minority yes) mixed factors ANOVA. Encoding task and response were repeated measures variables. In this analysis, we report only on effects that involve the response variable since we have already examined the other variables in the previous analyses. There was a response main effect $(F(1,37)=5.35$, $\left.p<.05, \eta_{p}{ }^{2}=.13\right)$, which shows that more shared items were recalled if there was a majority of 'yes' responses $(M=3.73, S D=1.06)$ than if there was a minority of 'yes' responses $(M=3.19$, $S D=0.90)$ to the items. However, this was modified by a significant encoding task by response interaction, $(F(2,74)=11.44, p<.01$, $\left.\eta_{p}{ }^{2}=.24\right)$. As Table 3 shows, groups recalled more shared items in the SRE condition when the majority said 'yes' than when a minority responded with 'yes' $(F(1,38)=30.05, p<.01$, $\left.\eta_{p}{ }^{2}=.44\right)$. The difference between the majority 'yes' response and minority 'yes' response was not significant for either the GRE items $\left(F(1,38)<1, \eta_{p}{ }^{2}=.001\right)$ or the semantic items 
$\left(F(1,38)<1, \eta_{p}{ }^{2}=.02\right)$. Therefore, the results suggest that consensus about endorsement has an effect for SRE items, but not GRE or semantic items. There were no other significant effects involving the response variable.

One explanation for our finding on consensus has to do with favorability of the traits. As previously mentioned, individuals like to hold a favorable view of their personal identity (e.g. Skowronski et al., 1991) and social identity (e.g. Biernat et al., 1996). It is possible that one reason that participants recall more SRE-shared items when a majority responds with 'yes' than when a minority responds with 'yes' may have to do with likableness of the traits. In order to examine this possibility, we correlated 'yes' responses (i.e. $3 y, 2 y, 1 y$ and $0 y$ ) with likableness ratings from the Anderson (1968) ratings of personality traits. Table 4 shows that the SRE condition and the GRE condition both obtained positive correlations. That is, as the item's favorability increased so too did the number of participants who said 'yes' to it whereas the correlations for the semantic items are either nonsignificant or in the negative direction. Interestingly this shows that individuals said that traits with positive connotations applied to both their personal self and their collective self. However, only in the SRE condition did these positive connotations seem to translate into increased recall.

\section{Post-recall questionnaire analysis}

Although the post-recall questionnaire was done at the individual level, we averaged the three-group members' responses and performed

Table 3. Mean recall of shared items at the different levels of the encoding task and response

\begin{tabular}{lrrr}
\hline & \multicolumn{3}{c}{ Encoding task } \\
\cline { 2 - 4 } & Semantic & GRE & SRE \\
\hline Response & & & \\
Majority Yes & $2.33_{\mathrm{a}}$ & $3.38_{\mathrm{a}}$ & $5.46_{\mathrm{a}}$ \\
& $(1.71)$ & $(1.66)$ & $(1.62)$ \\
Minority & $2.74_{\mathrm{a}}$ & $3.44_{\mathrm{a}}$ & $3.38_{\mathrm{b}}$ \\
& $(1.79)$ & $(1.47)$ & $(1.74)$ \\
\hline
\end{tabular}

Notes: Columns with different subscripts are significantly different at $p<.05$. Standard deviations are in parentheses.
Table 4. Correlation between yes responses and likableness for shared information

\begin{tabular}{lccc}
\hline & \multicolumn{3}{c}{ Encoding task } \\
\cline { 2 - 4 } & Semantic & GRE & SRE \\
\hline Group type & & & \\
Interacting & .00 & $.51^{* *}$ & $.52^{* *}$ \\
& $(106)$ & $(124)$ & $(164)$ \\
Nominal & $-.23^{*}$ & $.57^{* *}$ & $.58^{* *}$ \\
& $(92)$ & $(142)$ & $(181)$ \\
\hline
\end{tabular}

$* p<.05 ; * * p<.01$.

Note: The $n$ is in parentheses.

all analyses at the group level. Question 1 asked participates how much they anticipated having to recall the items on a 1 (not at all) to 7 (completely) scale. An unequal variance independent $t$ test showed that interacting groups $(M=1.60$, $S D=0.81)$ were equally likely to expect a recall task as nominal groups $(M=1.35, S D=0.50)$ $(t(32)=1.16, p>.10$, Cohen's $\mathrm{D}=.37)$, thus indicating that we were successful in creating a surprise recall task. The next three questions asked participants how difficult it was to recall SRE items, GRE items, and semantic items on a 1 (easy) to 7 (difficult) scale. Using an equal variance $t$ test, there were no significant differences between the nominal group $\left(M_{S R E}=3.56\right.$, $\left.S D=0.83 ; M_{\text {semantic }}=5.23, S D=0.82\right)$ and interacting group $\left(M_{S R E}=3.47, S D=0.85 ; M_{\text {semantic }}=4.77\right.$, $S D=0.98)$ for the SRE items $(t(37)=-.356$, $p>.10$, Cohen's $\mathrm{D}=.11)$, and the semantic items $(t(37)=-1.59, p>.10$, Cohen's $\mathrm{D}=.51)$. However, the nominal group $(M=3.95, S D=0.74)$ found it significantly more difficult to recall GRE items than interacting groups $(M=3.37, S D=0.79)$ $(t(37)=-2.375, p<.05$, Cohen's $\mathrm{D}=.76)$. Also, participants were asked to rate their accuracy of recall on a 1 (very inaccurate) to 7 (very accurate) scale. Interacting groups $(M=4.75$, $S D=0.78$ ) rated themselves as being significantly more accurate than nominal groups $(M=3.79$, $S D=0.84)(t(37)=3.71, p<.01$, Cohen's $\mathrm{D}=1.19)$. Finally, only participants in the interacting groups were asked about how difficult it was to recall either 'information common to all group members' lists' or 'unique to each group member's list' on a 1 (easy) to 7 (difficult) scale. 
A dependent $t$-test showed that interacting groups found it easier to recall common items $(M=2.67, S D=0.79)$ than unique items $(M=4.57$, $S D=0.91)$ from their lists $(t(19)=7.06, p<.01$, Cohen's D = 2.23).

\section{Discussion}

Before addressing each hypothesis separately, we would like to highlight two important interrelated trends from our findings. First, we consistently found that participants were more likely to recall items from their SRE list than items from their GRE and semantic lists (See Tables 1 and 2). This recall pattern challenged our initial assumption that the SRE and GRE would have equally impacted the recall of information. Instead, we found a series of results that we would characterize as strongly supporting our SRE hypotheses and showing mixed support for our GRE hypotheses. Second, the collective information sampling literature is filled with variables that have failed to increase the recall of unshared information. Therefore, our finding that relating information to yourself (i.e. SRE) increases the recall of unshared information is a significant contribution to the collective information sampling literature.

\section{Individual recall}

Hypothesis 2 that an SRE and a GRE would occur at the individual level was supported. Our SRE finding represents a replication of a wellestablished finding (Symons \& Johnson, 1997). However, to the best of our knowledge, our study is the first replication of the GRE (Johnson et al., 2002). Although the GRE was robust in our study (i.e. we found it on all 6 forms), it was also weaker than in Johnson et al. In the Johnson et al. study that used university affiliation (Experiment 1 ), they found very similar recall levels for the SRE and the GRE. However, we found that individuals recalled marginally more SRE items than GRE items. Although both studies used similar samples (i.e. largely undergraduates from lower level psychology courses), it is possible that the participants in their study felt a greater identification with their university than did our participants. However, this is difficult to determine because neither study took a direct measure of group identification. Therefore, a future research area would be to examine if intensity of group identification affects the strength of the GRE.

\section{Group recall}

Hypotheses 1 and 4 Our research replicated previous findings for nominal groups to recall more information than interacting groups (Hypothesis 1) and for groups to recall more shared information than unshared information (Hypothesis 4).

Hypothesis 3 This hypothesis predicted that for overall recall the SRE and GRE would be observed for both nominal groups and interacting groups. Moreover, we also speculated that it was possible that group interaction might either accentuate or attenuate the SRE and the GRE. As expected, we found that the SRE and GRE occurred at the nominal group level. We also found that the SRE occurred in interacting groups, but we found no evidence to suggest that the SRE was either attenuated or accentuated due to group interaction. This finding is consistent with Weldon and Bellinger's (1997) finding that effects found at the individual level transfer to the group level in a continuous manner. However, we found no evidence for the GRE occurring in interacting groups, which shows that group interaction did attenuate the GRE.

Hypotheses 5-7 Hypothesis 5 was supported for the SRE because groups recalled more SREunshared items than semantic-unshared items. However, for the GRE it was not supported because groups did not recall more GRE-unshared items than semantic-unshared items. Hypothesis 6 was supported by finding that the SRE and the GRE both improved the recall of shared information relative to the semantic condition. However, although the GRE improved the recall of shared information, groups still recalled more SRE-shared items than GRE-shared items. Hypothesis 7 was not supported because we found no evidence to suggest the impact of the SRE and GRE was stronger for unshared information than shared information. 
Research question 1 We found that SRE items were more likely to be recalled if a majority of the group had said the item was self-referent than if a minority of the group had said the item was self-referent. We found no effects for consensus on the recall of the GRE items and semantic items.

\section{SRE and GRE}

In examining the data, we believe that the SRE was primarily influenced by individual-level factors and that the GRE was influenced by both group-level factors and individual factors. Therefore, in this section we focus on examining the individual-level first followed by group-level factors.

Individual-level analyses There are two pieces of information that make us believe that the SRE occurred primarily due to individual-level factors that occurred prior to recall. First, our finding that the SRE occurred whether group interaction did or did not (i.e. nominal group and individuals) occur makes us suspect that the superiority of the SRE is not dependent upon group interaction. Second, the effect size analysis suggests that the SRE occurred with about the same strength for both interacting and nominal groups. This finding is consistent with the past literature (e.g. Symons \& Johnson, 1997) that suggest that the SRE occurs because people engage in more organizational and elaborative processing of items related to themselves than the processing of semantic items. Moreover, it is possible that the general superiority of the SRE to the GRE is due to participants processing information about themselves more deeply than information about the group either due to greater knowledge or greater identification with the personal self than the social self.

A second explanation is more motivational in nature. Gaertner, Sedikides, Vevea, and Iuzzini's (2002) did a meta-analysis in which they contrasted whether people are more motivated by their personal self or their collective self. They found that people were more likely to defend against threats to their personal self than collective self and more likely to seek enhancements of their personal self than collective self. This explanation would be consistent with our finding that the SRE tended to dominate over other types of information used in this study. Moreover, it is also consistent with our analyses of SRE-shared items (i.e. Research question 1) which appeared to show a bias toward recalling positive items. Namely, participants showed a tendency to say that positive items described them and recalled these items more when a majority of the group agreed these items were descriptive.

Group-level explanation The pattern of the means largely suggest that the GRE did not have an impact upon the recall of interacting groups. This may have been due to some of the individual-level factors stated above. However, the finding that for overall recall the GRE occurred in nominal groups but not in interacting groups suggests that there was some form of process loss occurring when groups interacted. In this section, we explore some group-level explanations for this process loss.

We offered an evaluation apprehension explanation for why GRE items might not be recalled as often in interacting groups as nominal groups. Namely, groups might be biased toward recalling positive items and reluctant to recall negative items about their group. Consistent with this explanation, we did find that among GREshared items that group members were more likely to endorse positive traits as applying to their group. However, unlike the SRE items we found no evidence to support the contention that groups were more likely to recall GRE-positive traits than GRE-negative traits.

The other explanation that we offered for why the GRE might be attenuated in interacting groups dealt with production blocking. On the post-discussion recall, we asked how easy it was to recall SRE items, GRE items, and semantic items on a 1 (easy) to 7 (difficult) scale. We found that there was no difference between the nominal group and the interacting group for the semantic and SRE items; however, interacting groups found it easier to recall GRE items than nominal groups. This finding is akin to Clark and Stephenson's (1989) idea of testimonial validity, which is the connection between the correctness of a group's recall and their confidence. In our 
study, we would argue that interacting groups are showing testimonial invalidity because they believe it was easy to recall GRE items, but their actual recall does not support their contention.

One explanation for this testimony invalidity might have to do with social comparison processes (Festinger, 1954; Wood, 1989). Clark and Stephenson (1989) argue that one fundamental distinction between individual remembering and group remembering is that groups are more likely to engage in social comparison processes as a means of verifying the accuracy of their recall. We speculate that groups might engage in more detailed discussion and social comparison for GRE items because they relate more to the group than either SRE items or semantic items. This increased discussion may lead to increased confidence that they did a good job in recalling GRE items. However, in production blocking terms, the extra talking about each item may have 'blocked' the group members from recalling other GRE items and thus reduced recall.

Another explanation for not finding the GRE with interacting groups may have to do with the increased salience of the group to which people belong during the experiment. As participants became more aware of their group identity within the experiment, they may have become less focused on their affiliation with the university, which could have had the effect of reducing the recall of GRE items. However, in nominal groups, they do not have any competing identities because they have never worked in a group. ${ }^{5}$

Finally, the one exception for the impact of the GRE was for shared information in which both the interacting groups and nominal groups recalled more GRE items than semantic items. However, even in this case, the recall of GRE items was significantly lower than SRE items. Therefore, given the overall pattern of findings that suggest the GRE does not occur in interacting groups, we think further study needs to be done to see if this pattern replicates.

\section{Collective information sampling}

As noted earlier, previous research has established that groups do a poor job of pooling all their available information because they tend to focus on mentioning shared information more than unshared information (e.g. Stasser \& Titus, 2003). One implication of our findings is that making information self-referent tends to increase the recall of unshared information. One possible extension of our results would be to see if our results apply to decision-making groups. If our findings did extend to the decision-making groups then it might make groups more likely to mention unshared information which could also improve their decision-making ability.

We think that another interesting finding is that both nominal groups and interacting groups showed the same bias toward recalling shared information more than unshared information. We think this finding for nominal groups is not unexpected and is consistent with the CIS model proposed by Stasser and Titus (1987). Even in nominal groups, shared information is more available than unshared information, thus the sampling advantage of shared information over unshared information. However, we think this finding is interesting because it adds to recent research which has suggested that failure to achieve optimal information pooling may not only be a function of problems with the group interaction, but also due to individual-level factors (e.g. Greitemeyer \& Schulz-Hardt, 2003).

\section{Future research}

Although the GRE has less impact on the group recall of items, we think there are a couple of ways in which the GRE might have more of an impact upon recall and thus might serve as future avenues of research. First, as mentioned earlier, the strength of identification with a social group varies and therefore it is not difficult to imagine that, in other instances, group membership may exert a powerful influence on one's use of information. Additionally, it may be that increased group identification increases confidence of the group members in the accuracy of their recall, which may in turn increase group recall. Second, social identity theory (Hogg, 2003) suggests that when group identities are threatened they often are made more salient and are more likely to guide information processing. For example, the GRE might have had more 
of an effect in our study if the prestige of their school had been threatened in some manner. Third, the way that information is encoded might affect the strength of the GRE. In our study, because we used unshared information, we had to have participants complete the encoding task individually. It is possible that this puts more emphasis upon individual identity than group identity, which might explain the superiority of the SRE over the GRE. However, if a group was asked to encode GRE items together (i.e. the group has to make a decision about whether a group identity possesses a certain trait) then this might lead to a stronger effect of the GRE.

A limitation of our study is that we did not collect any process measures. Therefore, future research should use videotapes or audiotapes to collect process measures to examine in more detail how the SRE and GRE affect the recall of information. In particular, we think that process measures could be particularly useful in investigating why interacting groups showed signs of the SRE, but not the GRE. For example, researchers could more directly determine to what degree favorability of the items affects the recall of SRE and GRE items. Additionally, we have presented several admittedly very speculative arguments about why the SRE uniformly increased recall and the GRE had a mixed impact upon recall. Therefore, future research that directly examines process measures is needed to see whether any of our proposed explanations might contribute to how the SRE and GRE affect group recall.

Finally, although this study used only oneword personality traits, we believe our findings may have implications for more applied areas. For example, two lines of research suggest that the SRE and GRE might affect personnel selection. First, the interpersonal attraction literature suggests that similarity is a factor in attraction (e.g. Caspi \& Herbener, 1990). Second, the Attraction-Selection-Attrition (ASA) model (Schneider, Goldstein \& Smith, 1995) postulates that organizations may end up with a homogeneous workforce because they hire and retain individuals who are similar to the organization. Therefore, we speculate that during personnel selection individuals and groups might think about SRE-like questions (e.g. Is this person similar to me? Can I work with this person?) or GRE-like questions (e.g. Will this person fit in with the organization? Does this person share the same values as the organization?). Our line of reasoning suggests that future research may wish to examine how the SRE and GRE affect which information is discussed about applicants and whether there are attempts to distort information. Additionally, researchers might also examine how the SRE and GRE affect evaluative judgments of job applicants.

\section{Notes}

1. Six participants were eliminated for one or more procedural reasons. Some participants were eliminated because they failed to keep up with the pace of the experimenter when going through the stimulus materials. Therefore, it is uncertain both as to whether these participants saw all the items on the list and how long they had seen each item. Participants were eliminated if they had been in one of the authors' classes that dealt with the topics of group memory and/or collective information sampling because it was likely this knowledge would influence the participant's responses. Finally, participants in the interacting groups always recalled the information in front of others and therefore, it is possible that social facilitation effects (Geen, 1989) might increase their recall. Therefore, in order to control for social facilitation effects, we eliminated any individuals who completed the recall alone from the nominal group. Another factor that limits our formation of nominal groups is exposure to unshared information. You cannot put people into the same group if their unshared information would be redundant because it would make the information partially shared. This resulted in five people being left over after nominal groups were formed.

2. We used this sequential process to mirror as closely as possible the formation of our interacting groups. However, toward the end of the experiment there were some minor violations of this 'sequential' rule due to two reasons. First, because as described in Note 1 some participants had to be dropped, it affected our ability to follow this sequential procedure. Second, the classes we approached for volunteers for this study were largely 
from freshman level classes. However, we did approach one class that was a junior level class. From this junior level class, we obtained two interacting groups and therefore, we went partially out of order to make sure and create two nominal groups containing students from the junior class.

3. In coding the nominal groups, we noticed that an individual occasionally would recall a piece of unshared information that was not on their original stimulus list. Given that the instance of this occurring was low ( $M=0.58$ per group) and that overall intrusion rates for nominal groups were high $(M=9.84)$, we assumed this was due to a group member guessing about a piece of unshared information that was not on their list, but happened to be on another group member's list. However, in the interacting groups, we could not discern this type of information because we have only a group recall. However, presumably interacting groups would also have items that group members guessed at and got correct. Therefore, in order to make the comparison between nominal and interacting groups fair, we elected to code these items as correct in the nominal groups.

4. For recalled items, most of the disagreements that were not about the form of the word involved one of the coders either omitting items or misreading items.

5. We wish to thank Scott Tindale for this suggestion.

\section{Acknowledgements}

Portions of this article were presented at the 16th Annual meeting of the American Psychological Society, Chicago, Il.

We would like to thank Gail Vinci and Tom Fioti for the development of the stimulus material and Wendel Cox for his help on resolving some of the disagreements between coders. We would also like to thank the three anonymous reviewers for their insights on this study.

\section{References}

Anderson, N. H. (1968). Likableness ratings of 555 personality-trait words. Journal of Personality and Social Psychology, 9, 272-279.

Basden, B, H., Basden, D. R., Bryner, S., \& Thomas, R. L. (1997). A comparison of group and individual remembering: Does collaboration disrupt retrieval strategies? Journal of Experimental Psychology: Learning, Memory and Cognition, 23, 1176-1189.

Biernat, M., Vescio, T. K., \& Green, M. L. (1996). Selective self-stereotyping. Journal of Personality and Social Psychology, 71, 1194-1209.

Brewer, M. B. (2003). Optimal distinctiveness, social identity, and the self. In M. R. Leary \& J. P. Tangney (Eds.), Handbook of self and identity (pp. 480-491). New York: Guilford.

Caspi, A., \& Herbener, E. S. (1990). Continuity and change: Assortative marriage and the consistency of personality in adulthood. Journal of Personality and Social Psychology, 58, 250-258.

Clark, N. K., \& Stephenson, G. M. (1989). Group remembering. In P. B. Paulus (Ed.), Psychology of group influence (pp. 357-391). Hillsdale, NJ: Erlbaum.

Clark, N. K., Stephenson, G. M., \& Kniveton, B. H. (1990). Social remembering: Quantitative aspects of individual and collaborative remembering by police officers and students. British Journal of Psychology, 81, 73-94.

Craik, F. I. M., \& Tulving, E. (1975). Depth of processing and the retention of words in episodic memory. Journal of Experimental Psychology: General, 104, 268-294.

Diehl, M., \& Stroebe, W. (1987). Productivity loss in brainstorming groups: Toward the solution of a riddle. Journal of Personality and Social Psychology, 53, 497-509.

Festinger, L. (1954). A theory of social comparison processes. Human Relations, 7, 117-140.

Gaertner, L., Sedikides, C., Vevea, J., \& Iuzzini, J. (2002). The 'I', the 'we', and the 'when': A meta-analysis of motivational primacy in self-definition. Journal of Personality and Social Psychology, 83, 574-591.

Geen, R. G. (1989). Alternative conceptions of social facilitation. In P. B. Paulus (Ed.), Psychology of group influence (pp. 15-51). Hillsdale, NJ: Erlbaum.

Greitemeyer, T., \& Schulz-Hardt, S. (2003). Preference-consistent evaluation of information in the hidden profile paradigm: Beyond group-level explanations for the dominance of shared information in group discussion. Journal of Personality and Social Psychology, 84, 322-339.

Hartwick, J., Sheppard, B. H., \& Davis, J. H., (1982). Group remembering: Research and implications. In R. A. Guzzo (Ed.), Improving group decision making in organizations (pp. 41-72). New York: Academic Press. 
Hinsz, V. B. (1990). Cognitive and consensus processes in group recognition memory performance. Journal of Personality and Social Psychology, 59, 705-718.

Hinsz, V. B., Tindale, R. S., \& Vollrath, D. A. (1997). The emerging conceptualization of groups as information processors. Psychological Bulletin, 121, 43-64.

Hogg, M. A. (2003). Social identity. In M. R. Leary \& J. P. Tangney (Eds.), Handbook of self and identity (pp. 462-479). New York: Guilford.

Johnson, C., Gadon, O., Carlson, D., Southwick, S., Faith, M., \& Chalfin, J. (2002). Self-reference and group membership: Evidence for a groupreference effect. European Journal of Social Psychology, 32, 261-274.

Karau, S. J., \& Williams, K.D. (1993). Social loafing: A meta-analytic review and theoretical integration. Journal of Personality and Social Psychology, 65, 681-706.

Klein, S. B., \& Kihlstrom, J. F. (1986). Elaboration, organization, and the self-reference effect in memory. Journal of Personality and Social Psychology, 115, 26-38.

Klein, S. B., \& Loftus, J. (1988). The nature of self-referent encoding: The contributions of elaborative and organizational processes. Journal of Personality and Social Psychology, 55, 5-11.

Rogers, T. B., Kuiper, N. A., \& Kirker, W. S., (1977). Self-reference and the encoding of personal information. Journal of Personality and Social Psychology, 35, 677-688.

Schneider, B., Goldstein, H. W., \& Smith, D. B. (1995). The ASA framework: An update. Personnel Psychology, 48, 747-773.

Skowronski, J. J., Betz, A. L., Thompson, C. P., \& Shannon, L. (1991). Social memory in everyday life: The recall of self-events and other-events. Journal of Personality and Social Psychology, 60, 831-843.

Stasser, G., \& Titus, W. (1987). Effects of information load and percentage of shared information on the dissemination of unshared information during group discussion. Journal of Personality and Social Psychology, 53, 81-93.

Stasser, G., \& Titus, W. (2003). Hidden profiles: A brief history. Psychological Inquiry, 14, 304-313.

Steiner, I. D. (1972). Group processes and productivity. San Diego, CA: Academic Press.

Stephenson, G. M., Clark, N. K., \& Wade, G. S. (1986). Meetings make evidence? An experimental study of collaborative and individual recall of a simulated police interrogation. Journal of Personality and Social Psychology, 50, 1113-1122.

Stewart, D. D. (1998). Stereotypes, negativity bias, and the discussion of unshared information in decision-making groups. Small Group Research, 29, 643-668.

Stewart, D. D., \& Stasser, G. (1995). Expert role assignment and information sampling during collective recall and decision making. Journal of Personality and Social Psychology, 69, 619-629.

Stewart, D. D., \& Stewart, C. B. (2001). Group recall: The picture-superiority effect with shared and unshared information. Group Dynamics: Theory, Research and Practice, 5, 48-56.

Stewart, D. D., Stewart, C. B., Tyson, C., Vinci, G., \& Fioti, T. (2004). Serial position effects and the picture-superiority effect in the group recall of unshared information. Group Dynamics: Theory, Research, and Practice, 8, 166-181.

Symons, C. S., \& Johnson, B. T. (1997). The selfreference effect in memory: A meta-analysis. Psychological Bulletin, 121, 371-394.

Tindale, R. S., \& Sheffey, S. (2002). Shared information, cognitive load, and group memory. Group Processes $\mathcal{E}$ Intergroup Relations, 5, 5-18.

Vollrath, D. A., Sheppard, B. H., Hinsz, V. B., \& Davis, J. H. (1989). Memory performance by decision-making groups and individuals. Organizational Behavior and Human Decision Processes, 43, 289-300.

Wegner, D. M. (1986). Transactive memory: A contemporary analysis of the group mind. In B. Mullen \& G. R. Goethals (Eds.), Theories of group behavior (pp. 185-208). New York: Springer-Verlag.

Wegner, D. M., Erber, R., \& Raymond, P. (1991). Transactive memory in close relationships. Journal of Personality and Social Psychology, 61, 923-929.

Weldon, M. S. (2001) Remembering as a social process. In D. Medin (Ed.), The psychology of learning and motivation (Vol. 40, pp. 67-120). San Diego, CA: Academic Press.

Weldon, M. S., \& Bellinger, K. D. (1997). Collective memory: Collaborative and individual processes in remembering. Journal of Experimental Psychology:Learning, Memory and Cognition, 23, 1160-1175.

Weldon, M.S., Blair, C., \& Huebsch, P. D. (2000). Group remembering: Does social loafing underlie collaborative inhibition? Journal of 
Experimental Psychology: Learning, Memory and Cognition, 26, 1568-1577.

Wittenbaum, G. M., Hollingshead, A. B., \& Botero, I. C. (2004). From cooperative to motivated information sharing in groups: Moving beyond the hidden profile paradigm. Communication Monographs, 71, 286-310.

Wood, J. V. (1989). Theory and research concerning social comparisons of personal attributes. Psychological Bulletin, 106, 231-248.

Paper received 9 May 2003; revised version accepted 26 July 2006.

\section{Biographical notes}

DENNIS D. STEWART is an associate professor of psychology at the University of Minnesota, Morris Campus. His research areas include group memory and group decision making.

CHERYL B. STEWART is an assistant professor of psychology at the University of Minnesota, Morris Campus. Her research interests include group memory and ecological psychology.

JASON WALDEN is an undergraduate student at the University of Minnesota, Morris Campus. 